\title{
Connecting Phase Stability to the Grain Growth Behavior of Ni-W Alloys
}

\author{
Christopher J. Marvel, Denise Yin, and Martin P. Harmer
}

Department of Materials Science and Engineering, Lehigh University, Bethlehem PA 18015 USA

Nanocrystalline materials are beneficial due to their promising mechanical properties. However, selecting proper alloy compositions to limit unwanted grain growth has become a challenge because of increasing difficulties in understanding nanocrystalline thermodynamics and kinetics. There is a strong dependence on accurate phase diagrams to correctly predict at which compositions certain thermal stability mechanisms are most likely active. Regardless of the stability mechanism, proper knowledge of the phase diagram is paramount to choose the best alloy composition.

Ni-W alloys are classified as thermodynamically stable materials because W-segregation lowers the specific energy of the grain boundaries and reduces the driving force for grain growth [1]. However, the binary $\mathrm{Ni}-\mathrm{W}$ phase diagram has been questioned in regard to the existence of high $\mathrm{W}$-content intermetallics, namely $\mathrm{NiW}$ and $\mathrm{NiW}_{2}$ [2,3]. If the phase diagram is indeed inaccurate, some phases may form before they are anticipated and de-stabilize the microstructure. Considering that the phase diagram is an essential predictive tool for any nanocrystalline material, this work has taken a comprehensive approach to characterize several heat-treated $\mathrm{Ni}-\mathrm{W}$ alloys to aide in proper design of this nanocrystalline system.

Electrodeposited and DC magnetron sputtered alloys of differing $\mathrm{W}$ content were annealed in a reducing $\mathrm{N}_{2}-5 \% \mathrm{H}_{2}$ atmosphere at several temperatures to track $\mathrm{Ni}-\mathrm{W}$ phase evolution. Aberration-corrected scanning transmission electron microscopy (STEM) was the primary tool to characterize the microstructures and identify inconsistences of the binary phase diagram.

First and foremost, several unexpected impurity phases that are not found on the phase diagram were identified. In agreement with Cury et al (2009), the intermetallic phase NiW was not observed in alloys exceeding 20 at $\% \mathrm{~W}$, but instead, the impurity carbide phase $\mathrm{Ni}_{6} \mathrm{~W}_{6} \mathrm{C}$ was found [3]. Furthermore, the $\mathrm{Ni}_{6} \mathrm{~W}_{6} \mathrm{C}$ was identified in both the electrodeposited and sputtered alloys annealed at $700{ }^{\circ} \mathrm{C}$, which suggests that the $\mathrm{Ni}_{6} \mathrm{~W}_{6} \mathrm{C}$ precipitation may be more widespread than currently realized. Figures $1 \mathrm{a}$ (electrodeposited) and $1 \mathrm{~b}$ (sputtered) highlight $\mathrm{Ni}_{6} \mathrm{~W}_{6} \mathrm{C}$ via bright contrast in STEM-HAADF images. Interestingly, the electrodeposited STEM-HAADF image featured a pure $\mathrm{W}$ phase as well. To prove that the impurity phase was $\mathrm{Ni}_{6} \mathrm{~W}_{6} \mathrm{C}$ and not NiW, STEM-EDS, atomic resolution imaging and selected area diffraction patterns confirmed that the composition and crystal structure was indeed $\mathrm{Ni}_{6} \mathrm{~W}_{6} \mathrm{C}$ [4]. Besides $\mathrm{Ni}_{6} \mathrm{~W}_{6} \mathrm{C}, \mathrm{W}$-rich oxide particles were consistently observed in electroplated and sputtered alloys. In electrodeposited alloys, oxide particles were measured to be of appropriate size and volume fraction to pin grain boundaries and limit grain growth [5]. In sputtered alloys, the oxide particles were observed on the columnar grain boundaries, as seen in Figure 1b. Perhaps the most important observation regarding the nanoscale oxide particles was that W-segregation to oxide phase boundaries was consistently observed. Thus, an indirect thermal stability mechanism of phase boundary segregation can reduce grain growth rates because the particles are now resistant to coarsening. Lastly, and specific to the sputtered alloys, Ar pores decorated the columnar grain boundaries. Similar to the oxide particles, it is probable that the Ar pores act as pinning agents to slow grain growth. 
In contrast to $\mathrm{NiW}$, the intermetallic $\mathrm{Ni}_{4} \mathrm{~W}$ was confirmed to exist. In addition, the disordering transformation that occurs between $700{ }^{\circ} \mathrm{C}$ and $1000{ }^{\circ} \mathrm{C}$ was confirmed. Figure 2 shows that at $700{ }^{\circ} \mathrm{C}$ there are two $\mathrm{Ni}_{4} \mathrm{~W}$ variants that are clearly observable, and after heating above $1000^{\circ} \mathrm{C}$, the $\mathrm{W}$ atoms are dissolved back into a disordered solid solution. Older reports have also observed $\mathrm{Ni}_{4} \mathrm{~W}$ chemical ordering, but they did not have the capability to characterize the atomic structure [6]. Interestingly, alloys within the $\mathrm{Ni}(\mathrm{W})$ and $\mathrm{Ni}_{4} \mathrm{~W}$ two-phase region exhibited abnormal grain growth at $700{ }^{\circ} \mathrm{C}$.

Overall, this study has re-evaluated the Ni-W binary phase diagram, identified the most likely impurity phases, and connected the new findings to nanocrystalline grain growth behavior.

\section{References:}

[1] AJ Detor and CA Schuh, Acta Materialia 55 (2007) 371

[2] SVN Naidu, AM Sriramamurthy, PR Rao, Journal of Alloy Phase Diagrams. 2 (1986) 1

[3] R Cury, J-M Joubert, S Tusseau-Nenez, E Leroy, A Allavena-Valette, Intermetallics 17 (2009) 174

[4] CJ Marvel, PR Cantwell, MP Harmer, Scripta Materialia 96 (2015) 45

[5] CJ Marvel, D Yin, PR Cantwell, MP Harmer, Mat. Sci. Eng. A In press

[6] JC Williams, G Garmong, Metallurgical Transactions A 6 (1975) 1699

[7] The authors acknowledge funding from the ONR-MURI program (grant no. N00014-11-0678)
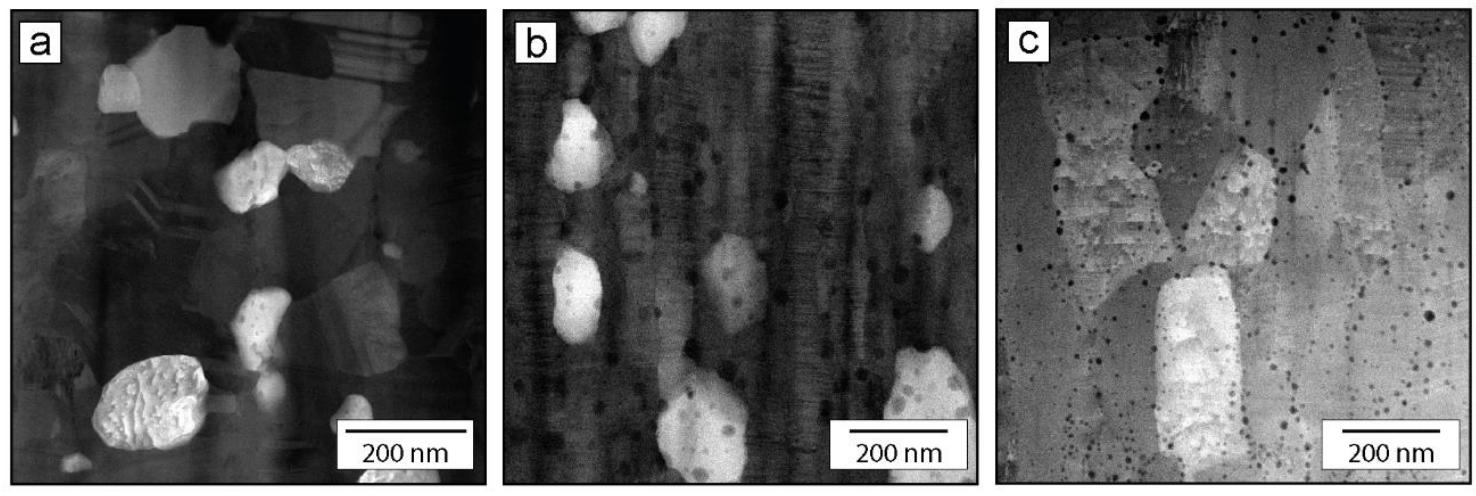

Figure 1. STEM-HAADF images that aided in the identification of impurity phases in electrodeposited and sputtered Ni-W alloys: (a) $\mathrm{Ni}_{6} \mathrm{~W}_{6} \mathrm{C}$, (b) $\mathrm{Ni}_{6} \mathrm{~W}_{6} \mathrm{C}$ and WOx, and (c) Ar pores.
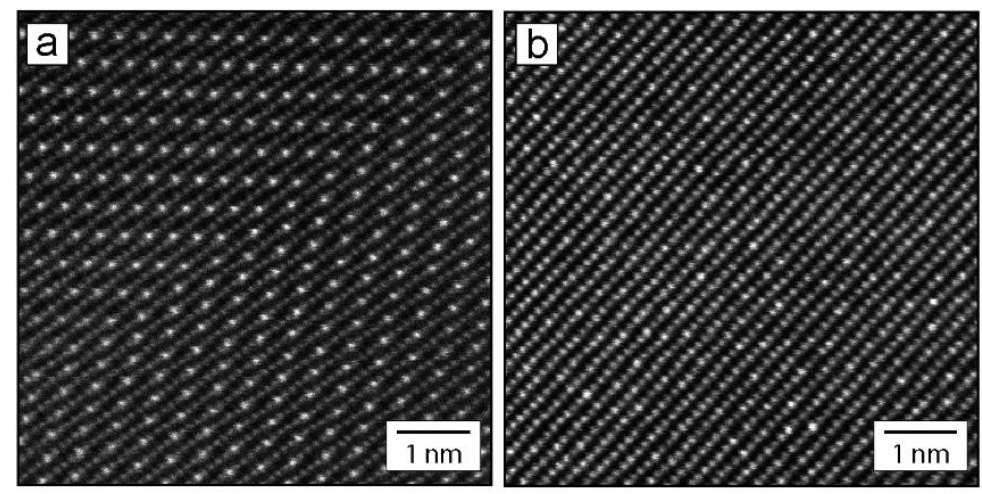

Figure 2. STEM-HAADF images that show the ordering transition of $\mathrm{Ni}_{4} \mathrm{~W}$ after heat treating in $\mathrm{N}_{2}-5 \%$ $\mathrm{H}_{2}$ for $24 \mathrm{hrs}$. 